\author{
생물학적 축산폐수 처리공정의 자동제어 방법 및 \\ 제어 인자의 안정성 \\ 김원용* . 정재현** . 라창식* \\ 강원대학교 동물자원학부*, 주식회사 하이셈텍**
}

\title{
Real-time Control of Biological Animal Wastewater Treatment Process and Stability of Control Parameters
}

\author{
W. Y. Kim*, J. H. Jung** and C. S. Ra*
}

Division of Animal Resource Science, Kangwon National University*,

Hycem tech. Ltd., Yuseong Daejeon 100**

\begin{abstract}
The feasibility and stability of $\mathrm{ORP}, \mathrm{pH}(\mathrm{mV})$ and $\mathrm{DO}$ as a real-time control parameter for SBR process were evaluated in this study. During operation, NBP(nitrogen break point) and NKP(nitrate knee point), which reveal the biological and chemical changes of pollutants, were clearly observed on ORP and $\mathrm{pH}(\mathrm{mV})$-time profiles, and those control points were easily detected by tracking the moving slope changes(MSC). However, when balance of aeration rate to loading rate, or to OUR(oxygen uptake rate), was not optimally maintained, either false NBP was occurred on ORP and DO curves before the appearance of real NBP or specific NBP feature was disappeared on ORP curve. Under that condition, however, very distinct NBP was found on $\mathrm{pH}(\mathrm{mV})$-time profile, and stable detection of that point was feasible by tracking MSC. These results might mean that $\mathrm{pH}(\mathrm{mV})$ is superior real-time control parameter for aerobic process than ORP and DO. Meanwhile, as a real-time control parameter for anoxic process, ORP was very stable and more useful parameter than others. Based on these results, a stable real-time control of process can be achieved by using the ORP and $\mathrm{pH}(\mathrm{mv})$ parameters in combination rather than using separately. A complete removal of pollutants could be always ensured with this real-time control technology, despite the variations of wastewater and operation condition, as well as an optimization of treatment time and capacity could be feasible.
\end{abstract}

(Key words : NBP, NKP, SBR, ORP, $\mathrm{pH}(\mathrm{mV})$, MSC)

$$
\text { I 서 론 }
$$

SBR(sequencing batch reactor) 시스템은 단일 반응조에서 유기물, 질소, 인의 제거와 슬러지 침전 및 유출수 배출 등의 모든 처리가 이루어 지는 처리공정이다. SBR 공정은 원수 특성이나 기후여건 등에 따라 운전 모드의 전환이 쉽고, 기존 활성 슬러지 공정에 비해 슬러지 bulking 현상이 적으며, 유량 변동이 있는 조건에서도
효율적인 운전이 가능한 장점을 지니고 있다 (Okada 등, 1984). 현재 국내의 경우에는 공주, 홍성 등의 축산폐수공공처리장에서 $\mathrm{SBR}$ 이 활 용되고 있으며, 향후 축산폐수에의 적용이 지 속적으로 증가할 것으로 여겨진다. SBR을 이용 한 축산폐수 처리에 있어서 더욱 엄격해진 방 류수질을 항상 만족시키기 위해서는 높은 처리 효율을 항상 유지할 수 있어야 할 뿐만 아니라 에너지 사용 및 운전비용의 최소화와 더불어

Corresponding author : ChangSix Ra, Division of Animal Resource Science, Kangwon National Uniersity, Chunchon, 200-701, Korea. Tel : (033)250-8618, Fax : (033)244-2433, E-mail: changsix@ kangwon.ac.kr 
처리용량 최대화가 가능하여야 한다. 특히, 계 절적 요인 및 축종과 가축연령, 농가의 가축사 양관행, 축사구조, 분뇨취급 형태 등에 따라 매 우 가변적이고(Ra 등, 1998), 때때로 가축 전염 성 질병의 발생으로 소독약을 다량 함유하고 있기도 하는 축산폐수를 효율적이고 안정적으 로 처리하기 위해서는 부하량이 가변적이고 시 스템의 조건이 수시로 변화하는 상황에서도 안 정적인 진단 · |어가 가능하여야 한다.

생물학적 처리공정에서 공정 상태를 실시간 으로 감시 및 제어하기 위한 인자로서 $\mathrm{pH}$, ORP(oxidation-reduction potential), DO의 효율성 이 많은 연구자에 의해 보고되어 왔다(Heduit and Thevenot, 1992; Al-Ghusain 등, 1994; Lo 등, 1994; Hao and Huang, 1996; Yu 등, 1997; Ra 등, 1998, 1999, 2000; Chen 등, 2002). 이들 연구결과를 검토해보면 처리공정 모니터 및 제 어에 있어서 $\mathrm{pH}, \mathrm{ORP}$ 모두 효율적인 자동제어 인자라는 의견과, $\mathrm{pH}$ 나 $\mathrm{ORP}$ 중 어느 하나가 다른 것에 비해 유용하다는 의견 등 연구조건 에 따라 서로 다른 결과를 보고하고 있다. 국 내의 몇몇 연구결과를 보면 이 등(2001)은 호기 적 단계에 있어서 $\mathrm{pH}$ 가 감소하는 최저점은 질 산화 종료 시점과 잘 일치는 하지만 $\mathrm{pH}$ 를 자 동제어 인자로 사용하기에는 어려움이 있는 반 면에 $\mathrm{ORP}$ 는 $\mathrm{pH}$ 와는 달리 안정적이고 유용한 호기적 단계의 자동제어 인자가 될 것으로 판 단하였으며 무산소 단계의 탈질완료시점 인식 에도 ORP가 매우 유용하다고 하고 있다. 서 등 (2000)도 탈질과정 중 $\mathrm{pH}$ 를 측정하여 탈질산화 완료시점을 찾을 수 있으나 자동제어 인자로 사용하기에는 ORP가 훨씬 안정적이라고 보고 하고 있다. 그러나 임 등(1994)은 호기적 혹은 무산소 단계에 있어서 $\mathrm{ORP}$ 보다는 $\mathrm{pH}$ 에서 질 산화와 탈질 반응이 잘 나타나므로 $\mathrm{pH}$ 가 효율 적인 제어인자로 사용될 수 있다고 하였으며 특히 호기적 단계에서 $\mathrm{pH}$ 에서는 질산화 반응 의 완료시점인 $\mathrm{NBP}($ Nitrogen Break Point)가 잘 나타나지만 $\mathrm{ORP}$ 에서는 이 시점을 찾기 어렵다 고 보고하고 있다. 대체적으로 이러한 연구결 과들은 전체 공정의 제어인자로서 어느 것이 보다 안정적이며 유용한가를 검토하거나, 혹은
하나의 특정제어인자만을 가지고 시험하여 그 유용성을 평가한 것이라 할 수 있다. 그러나 실제로 SBR 처리공정은 매우 다양한 cycle이나 처리방법 혹은 다양한 조건의 운전모드를 가지 고 운전될 수 있기 때문에 어느 하나의 특정 인자가 전체 공정 제어에 적합한지를 평가하기 보다는 호기 혹은 무산소 등의 각 처리단계별 혹은 운전 조건별로 가장 안정적이고 적합한 제어인자를 확보하여 자동제어 및 운전상태 진 단에 활용하는 것이 바람직한 것으로 판단된 다. 따라서 본 연구에서는 pilot scale의 SBR을 이용하여 돈사 뇨 · l수를 처리하면서 각 처리 조건의 자동제어 인자로서의 $\mathrm{ORP}, \mathrm{pH}, \mathrm{DO}$ 의 안정성과 유용성을 비교 . !가 하였다.

\section{ㅍ 실험재료 및 방법}

\section{1. 처리시스템 설비 및 운전방법}

농장에서 사용되고 있지 않은 사일리지 저장 콘크리트 구조물을 개 - !수하여 총 용적 $39 \mathrm{~m}^{3}$ 의 2 단계 $\mathrm{SBR}$ 돈사폐수 처리시설로 전환하였 다. 설비된 처리시설은 1 차 $\mathrm{SBR}, 2$ 차 $\mathrm{SBR}$, 유 출수 저장조로 구성되었으며(Fig. 1), 운전기간 중 총 유효용적은 $23 \mathrm{~m}^{3}(1$ 차, 2 차 $\mathrm{SBR}$ 의 유효용 적은 각각 $\left.5 \mathrm{~m}^{3}, 18 \mathrm{~m}^{3}\right)$ 을 유지하였다. 처리시스 템으로의 공기공급을 위하여 1 차 SBR에 2 개, 2 차 $\mathrm{SBR}$ 에 4 개의 산기관을 설비하여 폭기시 균 일한 공기공급이 이루어지도록 하였으며, 각 $\mathrm{SBR}$ 에 수중 교반기를 설비하여 원활한 교반이

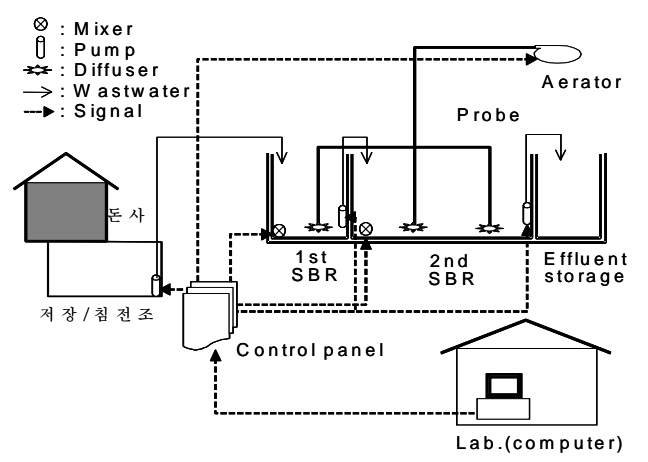

Fig. 1. Schematic of process with on-line computer system. 
이루어지도록 하였다. 폐수의 유입 및 유출은 수중펌프를 이용하여 이루어졌으며 각 펌프에 의한 유입, 유출 물량 및 작동 시간은 각 처리 조에 설비된 수위조절 센서에 의해 조절되도록 하였다.

폐수 처리과정 중 발생하는 특이적인 생물학 적 변화를 분석하기 위하여 2차 $\mathrm{SBR}$ 에 $\mathrm{ORP}$ $(\mathrm{Ag} / \mathrm{AgCl}), \mathrm{pH}, \mathrm{DO}$ probe를 설치하였으며 각각 의 probe에서 발생하는 전기적 신호를 컴퓨터 를 이용하여 1 분 간격으로 자동 모니터 및 저 장되도록 하였다.

2단계 SBR 시스템은 24시간/cycle을 기준으 로 1,2 차 $\mathrm{SBR}$ 모두 동일한 모드를 가지고 운 전하였으며 완전 질산화와 탈질이 발생할 시의 $\mathrm{ORP}$ 와 $\mathrm{pH}, \mathrm{DO}$ 를 모니터하기 위해 비교적 긴 HRT(21.7일)를 적용하여 시스템을 운전하였다. $\mathrm{SBR}$ 의 운전은 $\ulcorner$ eding $\rightarrow$ mnoxic $\rightarrow$ serobic $\rightarrow$ anoxic $\rightarrow$ settle $\rightarrow$ tischarge」 순으로 이루어졌 으며 세부적인 운전모드와 시간은 Table 1에 나타나 있다. 자동제어 인자로서의 $\mathrm{ORP}$ 와 $\mathrm{pH}$ 의 안정성 비교 시험은 2 개의 $\mathrm{SBR}$ 중 $1^{\mathrm{st}} \mathrm{SBR}$ 은 사용하지 않고 유입수가 직접 유효용적 $18 \mathrm{~m}^{3}$ 의 $2^{\text {nd }} \mathrm{SBR}$ 로 loading 되도록 하면서 다양
한 조건하에서의 $\mathrm{ORP}, \mathrm{pH}$ 및 $\mathrm{DO}$ 의 변화 패턴 을 시험/분석하여 이루어졌다. 효율적인 탈질을 얻기 위한 외부 탄소원의 공급은 2차 $\mathrm{SBR}$ 에서 만 influent 유입시 이루어졌으며 외부 탄소원으 로의 메탄올의 주입량은 $2.7 \mathrm{~L} / \mathrm{m}^{3}$ 이었다.

\section{2. 유입수 성상}

시험에 사용된 유입수로는 돼지 300두 규모 의 재래식 돈사에 설비되어있는 3단 저장조내 뇨 · l수가 사용되었다. 시험 기간동안 사용된 유입수 분석결과(Table 2), TOCs/ $\mathrm{NH}_{4}-\mathrm{N}$ 와 filterable $\mathrm{CODcr} / \mathrm{NH}_{4}-\mathrm{N}$ 의 비는 각각 $0.33,1.28$ 로 생 물학적 질소제거를 위해서는 탄소원이 부족함 을 알 수 있었다.

\section{3. 시료채취 및 분석 방법}

주 3회 간격으로 채취된 시료들의 TOCs, $\mathrm{CODcr}_{\mathrm{s}}, \mathrm{NH}_{4}-\mathrm{N}, \mathrm{NOx}-\mathrm{N}, \mathrm{PO}_{4}{ }^{3-}, \mathrm{MLSS}, \mathrm{MLVSS}$, $\mathrm{TS}$, TVS가 분석되었다. Total organic carbon의 분석은 TOC analyser(TOC-500A, Shimadzu)에 의해 분석되었으며 $\mathrm{NH}_{4}-\mathrm{N}, \mathrm{NOx}-\mathrm{N}, \mathrm{PO}_{4}{ }^{3-}$ 는 자

Table 1. Operation modes for two-stage SBR

\begin{tabular}{ccccccc}
\hline \multirow{2}{*}{$1^{\text {st }}$ reactor } & \multicolumn{2}{c}{$\begin{array}{c}\text { Feeding } \\
(0.22 \mathrm{hr})\end{array}$} & \multicolumn{2}{c}{$\begin{array}{c}\text { Reaction } \\
(23 \mathrm{hr})\end{array}$} & $\begin{array}{c}\text { Sludge settling } \\
(0.60 \mathrm{hr})\end{array}$ & $\begin{array}{c}\text { Discharge } \\
(0.18 \mathrm{hr})\end{array}$ \\
\cline { 2 - 7 } & $\&$ & $\mathrm{NA}$ & $\mathrm{NA}(6 \mathrm{hr})$ & $\mathrm{A}(11 \mathrm{hr})$ & $\mathrm{NA}(6 \mathrm{hr})$ & \multicolumn{2}{c}{$\mathrm{NA}$} & \\
$2^{\text {nd }}$ reactor & $\mathrm{NA}$ & $\mathrm{M}(6 \mathrm{hr})$ & $\mathrm{NM}(11 \mathrm{hr})$ & $\mathrm{M}(6 \mathrm{hr})$ & \multicolumn{2}{c}{$\mathrm{NM}$} \\
\hline
\end{tabular}

NA: no aeration, A: aeration, NM: no mixing, M: mixing.

Table 2. Influent characteristics and removal efficiencies

\begin{tabular}{|c|c|c|c|c|c|c|c|c|c|}
\hline \multirow{2}{*}{$\begin{array}{l}\text { Parameters } \\
\text { (mg/L) }\end{array}$} & \multicolumn{4}{|c|}{ Influent } & \multicolumn{4}{|c|}{ Effluent } & \multirow{2}{*}{$\begin{array}{c}\text { Removal } \\
\text { (\%) }\end{array}$} \\
\hline & Means & Min. & - Max. & $\begin{array}{c}\text { St. } \\
\text { Dev. } \\
\end{array}$ & Means & Min. & - Max. & $\begin{array}{c}\text { St. } \\
\text { Dev. }\end{array}$ & \\
\hline TOC & 119.4 & 61.0 & -204.0 & 39.8 & 39.6 & 26.0 & -53.0 & 6.8 & 66.8 \\
\hline CODcr & 458.6 & 232.0 & -776.0 & 160.9 & 158.3 & 35.0 & -342.0 & 78.2 & 65.5 \\
\hline $\mathrm{NH}_{4}^{+}-\mathrm{N}$ & 358.3 & 239.2 & -429.2 & 44.0 & 0.4 & 0.0 & -8.4 & 1.4 & 99.9 \\
\hline $\mathrm{NO}_{\mathrm{x}}{ }^{-}-\mathrm{N}$ & 0.1 & 0.0 & $\begin{array}{l}-\quad 1.1 \\
\end{array}$ & 0.2 & 15.0 & 0.0 & -78.7 & 14.1 & - \\
\hline $\mathrm{PO}_{4}^{3-}-\mathrm{P}$ & 23.2 & 4.4 & - 38.9 & 9.1 & 13.3 & 7.7 & -21.8 & 4.2 & 42.7 \\
\hline TS(g/L) & 1.2363 & 0.8433 & -5.3400 & 0.95 & 0.8143 & 0.1100 & -1.1433 & 0.17 & 34.1 \\
\hline TVS(g/L) & 0.3931 & 0.2333 & -1.6200 & 0.29 & 0.2271 & 0.0600 & - 0.3967 & 0.07 & 42.2 \\
\hline $\mathrm{SS}(\mathrm{g} / \mathrm{L})$ & 0.1038 & 0.0300 & -0.4900 & 0.09 & 0.0611 & 0.0000 & -0.3067 & 0.07 & 41.1 \\
\hline VSS(g/L) & 0.0628 & 0.0267 & -0.2000 & 0.04 & 0.0299 & 0.0000 & -0.0967 & 0.04 & 52.4 \\
\hline
\end{tabular}


동 수질 분석기(Quikchem 8000, Zellweger)를 이 용 - 석하였다. 이외 모든 분석은 standard method(A.P.H.A., 1995)에 준하여 분석하였다.

\section{III 결과 및 고찰}

\section{2단계 SBR 처리효율 및 제거특성}

Table 2는 돈사폐수에 대한 2단계 $\mathrm{SBR}$ 의 처 리효율을 나타낸 것이다. 처리시스템에서의 유 기화합물 제거효율은 약 $66 \%$ 수준으로 비교적 낮았으나 암모니아성 질소의 제거효율은 $99.9 \%$ 로 매우 높은 효율을 보였다. 각 처리조에서의 오염물질 제거특성을 나타낸 Fig. 2를 살펴볼 때 평균 수처리시간 4.7일 조건에서 운전된 $1^{\mathrm{st}}$ $\mathrm{SBR}$ 에서 $\mathrm{TOCs}$ 와 $\mathrm{CODcr}_{\mathrm{s}}$ 의 대부분이 제거되고, $1^{\text {st }} \mathrm{SBR}$ 에 비해 상당히 긴 처리시간(17일)이 주 어진 $2^{\text {nd }} \mathrm{SBR}$ 에서는 제거가 미미하였던 것으로 보아, 얻어진 낮은 유기화합물의 제거효율은 유입수의 성상 특성에 기인한 것으로 유입수 $\mathrm{CODCr}_{\mathrm{s}}$ 나 TOCs 의 상당 부분이 미생물이 분해 하기 어려운 난분해성 물질로 구성되었던 것으 로 판단된다. 또한 $2^{\mathrm{nd}} \mathrm{SBR}$ 에서의 낮은 유기화 합물 제거는 평균 $22 \mathrm{~g} / \mathrm{m}^{3} / \mathrm{d}\left(\mathrm{CODCr}_{\mathrm{s}}\right.$ 기준)로 낮 은 부하량이 유지됨에 따라 $1^{\text {st }} \mathrm{SBR}$ 에서 loading 된 대부분의 분해성 유기물이 제거되었기 때문이었던 것으로 여겨진다.

암모니아성 질소의 경우에는 거의 $100 \%$ 의 제거율을 보였는데, 이러한 높은 제거효율은

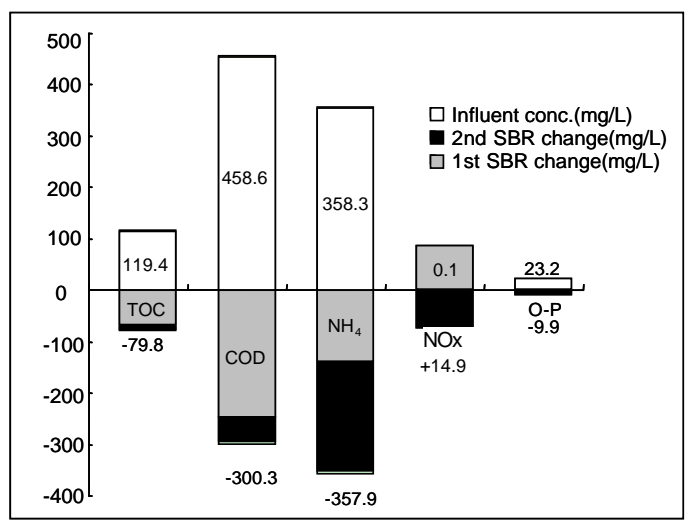

Fig. 2. Removal characteristics of pollutants in system.
특이적인 오염물질의 제거가 완료되는 시점을 표출하는 $\mathrm{ORP}$ 와 $\mathrm{pH}$ curve를 모니터하기 위해 긴 수처리 시간이 적용된 결과, 평균 $\mathrm{NH}_{4}-\mathrm{N}$ 의 부하량이 $17 \mathrm{~g} / \mathrm{m}^{3} / \mathrm{d}$ 로 낮았기 때문으로 판단된 다. 유출수내 평균 $\mathrm{NOx}-\mathrm{N}$ 의 농도는 $15 \mathrm{mg} / \mathrm{L}$ 로 비교적 좋은 탈질산화 과정이 유지되었으며 $\mathrm{PO}_{4}{ }^{3-}$ 의 제거효율은 약 $43 \%$ 수준, 고형물의 제 거효율은 $34 \sim 52 \%$ 수준을 나타내었다.

\section{2. $2^{\text {nd }} \mathrm{SBR}$ 에서의 $\mathrm{ORP}$ 와 $\mathrm{pH}$ 의 변화}

Fig. 3은 시스템 운전동안 $2^{\text {nd }} \mathrm{SBR}$ 에서 모니 터된 ORP와 $\mathrm{pH}-\mathrm{mV}$ 변화 curve중 오염물질의 특이적인 변화 시점을 잘 나타내는 profile을 나 타낸 것이다.

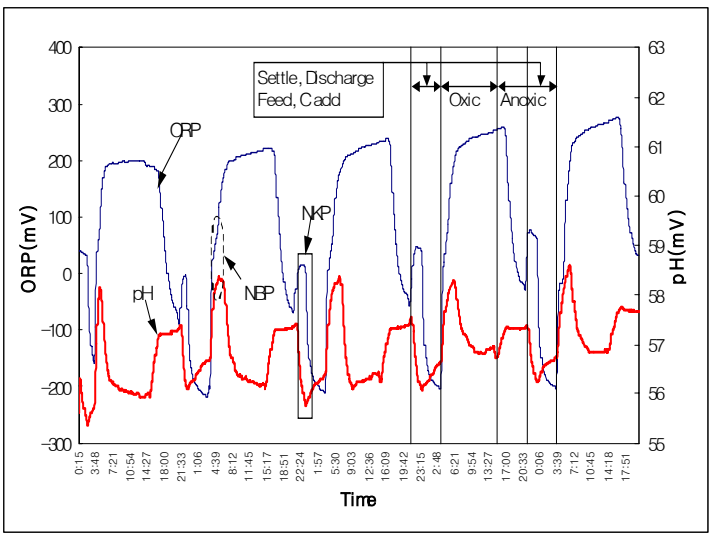

Fig. 3. Typical ORP- and $\mathrm{pH}(\mathrm{mV})$-time profile.

\section{(1) 무산소 조건에서의 ORP 및 $\mathrm{pH}(\mathrm{mV})$ - time profile의 변화}

호기적 처리단계의 종료 후 탈질을 위한 anoxic 상태에서의 ORP와 $\mathrm{pH}-\mathrm{mV}$ curve를 살펴 보면, 공기공급의 중단과 더불어 $\mathrm{pH}-\mathrm{mV}$ 는 증 가하다가 일정해지는데 이러한 $\mathrm{pH}-\mathrm{mV}$ 변화는 포기중지로 $\mathrm{CO}_{2}$ air-stripping이 중지되고 $\mathrm{CO}_{2}$ 의 재용해 현상이 일어남에 따라 발생하는 것으로 판단된다. $\mathrm{ORP}$ 는 폭기 중지 후에도 한동안 일 정한 패턴을 유지하다가 감소하였는데, 이는 포기중지로 인한 $\mathrm{O}_{2}$ 의 감소와 탈질산에 의한 것으로 여겨지나, $\mathrm{ORP}$ 가 크게 감소함에도 불구 하고 $\mathrm{pH}-\mathrm{mV}$ 가 감소하지 않고 일정하였던 것으 로 보아 활발한 탈질산은 이루어지지 않았음을 
알 수 있으며, 이는 탈질 과정에 관여하는 미 생물이 사용할 에너지원이 부족하였기 때문이 었던 것으로 판단된다.

슬러지의 침전과 최종 방류수의 배출이 이루 어진 후에 $1^{\mathrm{st}} \mathrm{SBR}$ 로부터 산화된 상등수가 유 입되고 동시에 탄소원으로 메탄올이 함께 유입 됨에 따라 $\mathrm{ORP}$ 는 상승하다가 갑작스런 하락을 보였는데, 이 시점이 바로 $\mathrm{NOx}-\mathrm{N}$ 의 고갈을 의 미하는 탈질 종료시점, 즉 Nitrate Knee Point (KNP)이다 (Koch 등, 1985; Wareham 등, 1993; $\mathrm{Ra}$ 등, 1999). 탈질 과정 중 $\mathrm{NOx}-\mathrm{N}$ 과의 반응으 로 나타나는 ORP curve의 변화는 항상 동일한 양상을 가지는 것이 아니라, 탈질이 진행되면 서 $\mathrm{ORP}$ 가 서서히 증가하는 경우, 변화가 없이 일정한 경우, 서서히 감소하는 경우의 3 가지 양상을 보이는데 각 변화양상이 나타나는 것은 처리조 내 오염물질의 산화정도 및 $\mathrm{NOx}-\mathrm{N}$ 의 농도 등 다양한 요인에 의해 달라진다. 그러나 $\mathrm{NKP}$ 가 나타나는 시점에서의 $\mathrm{ORP}$ 는 예외 없이 갑작스런 큰 폭의 하락을 보이게 된다. $\mathrm{pH}-\mathrm{mV}$ curve의 경우에는 탈질이 진행됨에 따라 지속 적으로 하락하다가 탈질이 종료되는 시점(NKP) 에서부터 다시 서서히 증가하는 양상을 띠는 데, 탈질 과정 중의 이러한 $\mathrm{pH}-\mathrm{mV}$ 의 감소는 탈질로 인한 알칼리도의 회복과 $\mathrm{NOx}-\mathrm{N}$ 농도 감소에 의한 것이며, 탈질 완료 후 나타나는 $\mathrm{pH}-\mathrm{mV}$ 의 증가는 인의 용출과 발효가 시작되기 때문인 것으로 판단된다.

\section{(2) 호기적 조건에서의 ORP 및 $\mathrm{pH}(\mathrm{mV})$ -} time profile의 변화

무산소 처리 후 호기적 처리가 시작됨에 따 라 ORP 및 $\mathrm{pH}-\mathrm{mV}$ 는 상승하다가 처리조내의 암모니아성 질소가 완전 산화되는 시점에서 $\mathrm{ORP}$ 는 다시 급상승하고 $\mathrm{pH}-\mathrm{mV}$ 는 상승이 중지 된 다음 하락하기 시작하는 특이적인 Nitrogen Break Point(NBP)가 발생하였다. ORP와 $\mathrm{pH}-\mathrm{mV}$ profile에서의 이러한 특이적인 $\mathrm{NBP}$ 의 발생은 처리조내의 질산화 미생물의 산소 소모량(oxygen uptake rate)이 암모니아성 질소의 고갈과 더불어 감소함에 따라 $\mathrm{O}_{2}$ 의 농도가 상대적으로 증가하고, 추가적인 $\mathrm{CO}_{2}$ stripping이 발생하게
되어 나타나는 것으로 판단된다. $\mathrm{NBP}$ 발생 이 후에도 호기적 처리가 계속됨에 따라 $\mathrm{ORP}$ 와 $\mathrm{pH}-\mathrm{mV}$ 의 변화가 비교적 일정해지는 plateau가 나타나는데 이 시점은 $\mathrm{DO}$ 농도가 포화되기 시작 하는 시점으로 처리조내에 biodegradable organic matter가 잔존한다면 지속적인 분해가 일어나게 된다. 호기와 무산소 조건에서의 특이적인 $\mathrm{ORP}$ 와 $\mathrm{pH}$ curve pattern에 대한 자세한 분석은 이 미 보고된 바 있다(Ra 등, 1998).

\section{MSC(Moving slope change) 이용시의 자 동제어 시점 발현 패턴}

Fig. 4는 Fig. 3에서 보여진 첫째, 둘째 cycle 의 ORP 및 $\mathrm{pH}-\mathrm{mV}$ curve와 $\mathrm{r}=10$ 조건 하에서 1 분 간격으로 모니터링 하면서 얻어진 Moving Slope Change(MSC)의 변화를 나타낸 것이다. 그림에서 알 수 있듯이 ORP와 $\mathrm{pH}-\mathrm{mV}$ curve 상에서 나타나는 특정오염물질의 제어시점은 MSC를 이용하여 쉽게 찾을 수 있음을 알 수 있다. 호기적 처리과정 중 $\mathrm{ORP}$ 에서 나타나는 $\mathrm{NBP}$ 는 MSC curve에서 뚜렷하게 나타나는 두 번째 positive peak이며, 무산소 상태에서 목격 되는 $\mathrm{NKP}$ 는 두 번째 negative peak임을 쉽게 발견할 수 있다. 또한 호기적 처리 중 $\mathrm{pH}-\mathrm{mV}$ 에서 발생하는 NBP는 MSC curve상에서 positive peak 다음에 나타나는 negative peak이고,

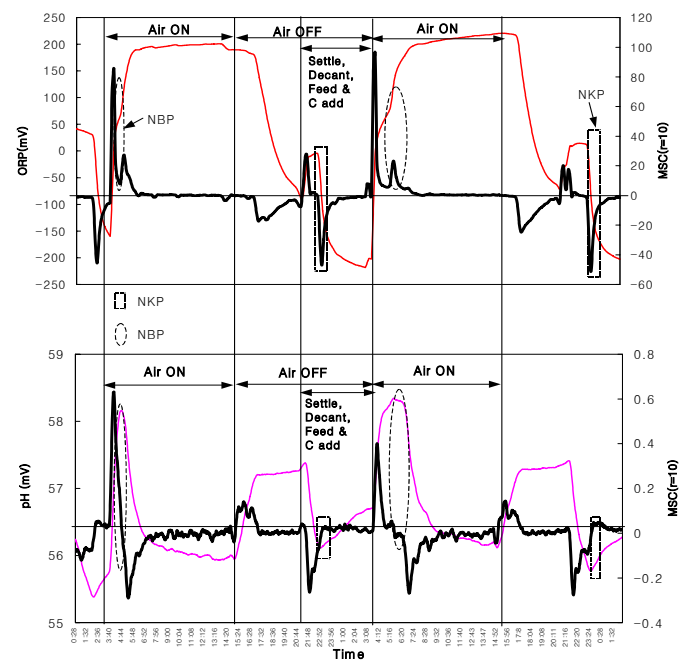

Fig. 4. Control strategy using MSC patterns. 
무산소 처리 중 발생하는 NKP는 negative peak 가 나타난 후 positive value로 전환되는 시점임 을 알 수 있다. 호기적 상태에서의 $\mathrm{pH}-\mathrm{mV}$ 변 화는 그림에서와 같이 포기시작과 함께 질산화 과정이 활발히 일어나 증가하다가 $\mathrm{NBP}$ 에서 감 소하는 경우와, 초기 $\mathrm{CO}_{2}$ air-stripping에 의해 감소하다가 질산화가 일어남에 따라 상승하고 $\mathrm{NBP}$ 에서 다시 감소하는 경우가 있는데, 어떤 경우이던 MSC상에서 positive peak가 발생한 후 에 나타나는 negative peak가 NBP이다. Fig. 4에 나타낸 것과 같은 비슷한 개념의 Moving range change(이동범위변화)를 이용하여 ORP상에서 발생하는 NBP와 NBP 발생 후 나타나는 RCMP (residual carbon manipulation point)를 실시간 제 어 시점으로 사용하여 시스템을 자동 제어하는 방법과, 그 효율성 및 $\mathrm{pH}-\mathrm{mV}$ 를 실시간 제어 parameter로 이용하여 제어시점을 인식하는 방 법은 이미 보고되었는데(Ra 등 1998, 1999, 2000) 이러한 연구보고들은 폐수를 시스템으로 유입시킬 때 $\mathrm{ORP}$ 를 이용하여 오염물질의 부하 량과 폐수 유입량을 유동적으로 조절하면서 주 어진 aeration rate 조건에서 지속적이고 안정적 인 ORP-time profile을 얻고 이를 이용하여 실 시간 자동 제어한 결과에 관한 것이다.

\section{4. $\mathrm{SBR}$ 자동제어 인자로서 $\mathrm{ORP}, \mathrm{DO}$ 와 $\mathrm{pH}$ 의 안정성}

자동제어 인자로서 $\mathrm{ORP}, \mathrm{DO}$ 와 $\mathrm{pH}$ 의 안정성 은 실험실 규모의 반응조와 pilot scale의 $2^{\text {nd }}$ $\mathrm{SBR}$ 을 이용하여 시험 - 1가하였다.

$\mathrm{ORP}$ 상에서 발생하는 $\mathrm{NBP}$ 를 실시간 제어 point로 이용하면서 안정적인 자동제어를 성취 하기 위해서는 우선 그림에서와 같이 안정적이 고 이상적인 curve를 얻을 수 있어야 한다. ORP에 영향을 주는 많은 인자들 중 오염물질 부하량과 포기량의 조화가 이루어지지 않고는 $\mathrm{NBP}$ 를 안정적으로 발생시키는 ORP curve를 얻 을 수는 없으며, 특히 축산폐수와 같이 가변적 인 폐수의 경우 시스템으로 일정량의 폐수가 유입될 때에도 그 부하량은 변화가 심할 수밖 에 없고, 이러한 상황 하에서의 일정한 aeration rate의 유지는 경우에 따라 시스템 OUR에 비해 과포기 조건이 되거나, 혹은 포기량이 부족한 조건이 될 수 있어 이상적인 ORP curve를 안정 적으로 얻기 어려울 수밖에 없다. Fig. 5와 6 은 이러한 것을 나타내는 것으로 $45 \mathrm{~L}$ 의 실험실 규모의 SBR을 이용 - 리로 다른 포기량 조건에 서 운전하면서 $\mathrm{O}_{2}$ 공급량, 즉 포기량이 $\mathrm{ORP}$ 및 $\mathrm{pH}-\mathrm{mV}$ curve pattern에 미치는 영향을 파악하 고 호기단계의 자동제어 인자로서의 $\mathrm{pH}-\mathrm{mV}$ 와 $\mathrm{ORP}$ 를 비교 평가한 것이다. Fig. 5 의 $6 \mathrm{~L} / \mathrm{min}$.의 aeration 조건에서 운전하면서 얻은 $\mathrm{ORP}$ 와 $\mathrm{pH}-$ $\mathrm{mV}$ 의 변화 pattern을 볼 때 Fig. 3과 4에서와 같이 포기량과 부하량이 조화를 이루며 매우 이상적이고 안정적인 curve가 얻어졌으나, 다소 낮은 포기율인 $2.5 \mathrm{~L} / \mathrm{min}$. 의 조건에서 운전하였 을 시에는 Fig. 6에서와 같은 curve 패턴의 변 화를 가져오면서 ORP curve 상에서 다수의 가짜 NBP가 발생함을 알 수 있었다. Fig. 5에서와 같이 이상적인 ORP curve가 발생할 때에는
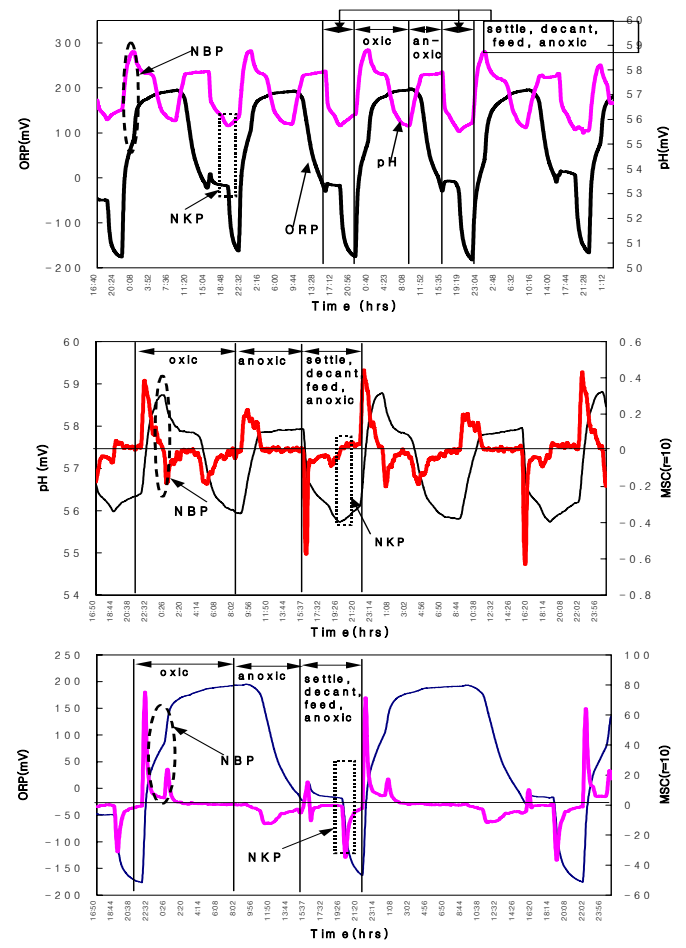

Fig. 5. ORP, $\mathrm{pH}(\mathrm{mV})$ and MSC patterns under a balanced condition(tested with labscale $45 \mathrm{~L}$ reactor). 

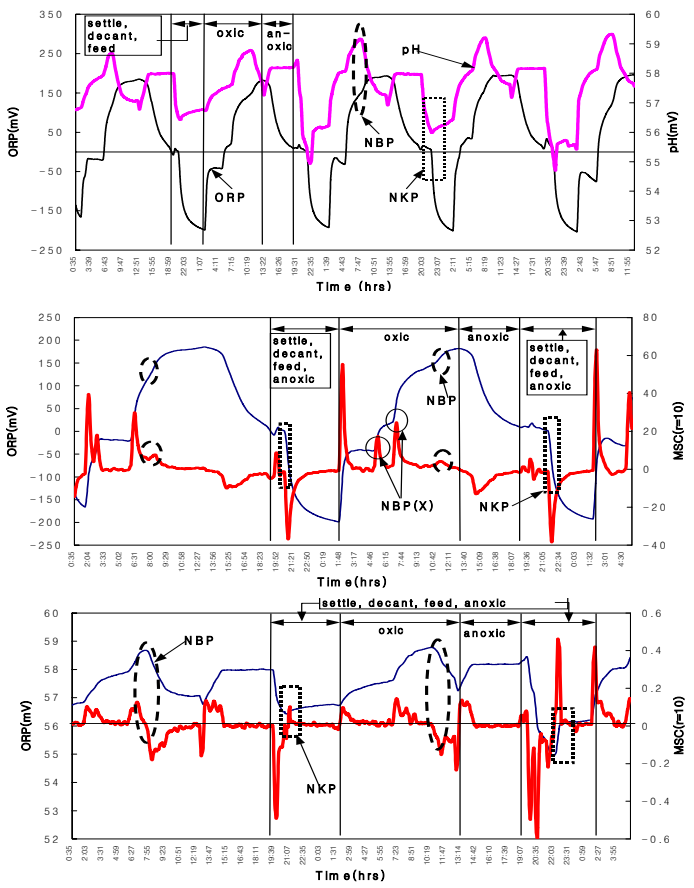

Fig. 6. ORP, $\mathrm{pH}(\mathrm{mV})$ and MSC patterns under low-aeration condition(tested with labscale $45 \mathrm{~L}$ reactor).

앞서 설명한 것과 같이 MSC의 두 번째 positive peak가 NBP이었으나 Fig. 6과 같이 낮은 aeration 하에서는 MSC curve 상에서 NBP를 나타 내는 peak를 확인하기 어려웠다. 그러나 $\mathrm{pH}-\mathrm{mV}$ curve의 경우에는 낮은 aeration rate 조건 하에 서도 $\mathrm{MSC}$ 상에서 $\mathrm{NBP}$ 를 확인할 수 있었으며 이상적인 curve인 Fig. 5에서와 같이 NBP는 바 로 positive peak 후에 발생하는 negative peak임 을 알 수 있었다. Fig. 5 와 6 에서의 curve 패턴 은 ORP에 대한 aeration rate, 즉 $\mathrm{O}_{2}$ 의 영향을 보여주는 것으로 처리조의 변화양상을 모니터 하여 시스템을 진단하고 최종 자동제어에 필요 한 이상적인 ORP curve를 얻기 위해서는 aeration rate이 적절히 조절되어야함을 보여주는 것 이라 할 수 있다. 이상적인 ORP curve를 나타 내는 적정 aeration rate을 처리조 단위용적 기 준으로 연구 - |시하기는 어려운 일인데, 이는 동일 aeration rate 조건 하에서도 포기장치와 산기관에 따라 산소 전달율이 다르며, 또한 처 리조 미생물의 OUR 및 오염물질 부하량 등에 따라 적정 aeration rate이 달라지기 때문이다.
따라서 이상적인 ORP curve를 얻기 위해서는 설비된 시스템을 가능한 한 일정한 부하량 조 건에서 운전하면서 $\mathrm{ORP}$ 와 $\mathrm{DO}$ 를 모니터 하여 결정하는 것이 바람직할 것으로 판단된다.

Fig. 7과 8은 실험재료 및 방법에 언급된 것과 같이 $2^{\text {nd }} \mathrm{SBR}$ 을 단일 $\mathrm{SBR}$ 로 이용하면서 시험 하여 얻어진 $\mathrm{ORP}, \mathrm{pH}, \mathrm{DO}$ curve를 나타낸 것 이다. Fig. 7에서 알 수 있는 것과 같이 Fig. 6 과 같은 $\mathrm{ORP}$ 및 $\mathrm{pH}-\mathrm{mV}$ curve를 나타내는 경 우에 있어서의 암모니아성 질소의 농도 변화와 ORP 및 $\mathrm{pH}-\mathrm{mV}$ curve 변화를 비교할 때 호기 적 처리 중 $\mathrm{ORP}$ 상에서 발생한 굴곡점은 질산 화가 종료되는 NBP가 아님을 확인할 수 있다. 반면 $\mathrm{ORP}$ 상에서 $\mathrm{NBP}$ 가 나타나지 않는 조건에 서도 $\mathrm{pH}-\mathrm{mV}$ curve에서는 질산화가 완료되는 시점인 NBP가 뚜렷하게 발생하는 것을 알 수 있다.

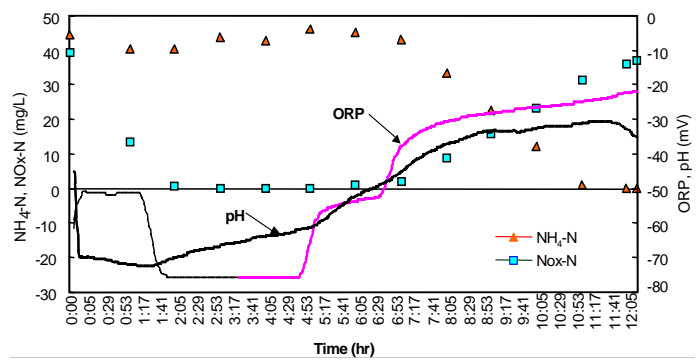

Fig. 7. Track of nitrogen and ORP/pH(mV) curves.

Fig. 8의 a, b, c는 호기적 처리과정 중에 주 로 나타나는 3 가지의 서로 다른 $\mathrm{ORP}, \mathrm{pH}-\mathrm{mV}$, DO curve 양상을 보여준다. Fig. 8a는 NBP가 $\mathrm{ORP}, \mathrm{pH}-\mathrm{mV}, \mathrm{DO}$ 에서 거의 동일한 시점에 발 생하는 것을, Fig. $8 \mathrm{~b}$ 는 $\mathrm{ORP}, \mathrm{pH}-\mathrm{mV}, \mathrm{DO}$ curve 가 각각 서로 다른 pattern을 보이는 경우를, Fig. 8c는 ORP와 $\mathrm{DO}$ 의 curve pattern은 비슷하 나 $\mathrm{pH}-\mathrm{mV}$ curve는 다른 양상을 나타내는 경우 를 보이고 있다. Fig. 8a를 볼 때 ORP에서 NBP 로 인식되는 굴곡점이 발생할 때 $\mathrm{pH}-\mathrm{mV}$ curve 에서 NBP 발생시 발견되는 감소 현상이 나타 나고 $\mathrm{DO}$ 에서도 $\mathrm{NBP}$ 발생이후 나타나는 $\mathrm{DO}$ 증가와 포화가 일어난 것으로 보아 $\mathrm{ORP}, \mathrm{DO}$, $\mathrm{pH}-\mathrm{mV}$ 에서 동시에 발생한 각각의 굴곡점이 바 

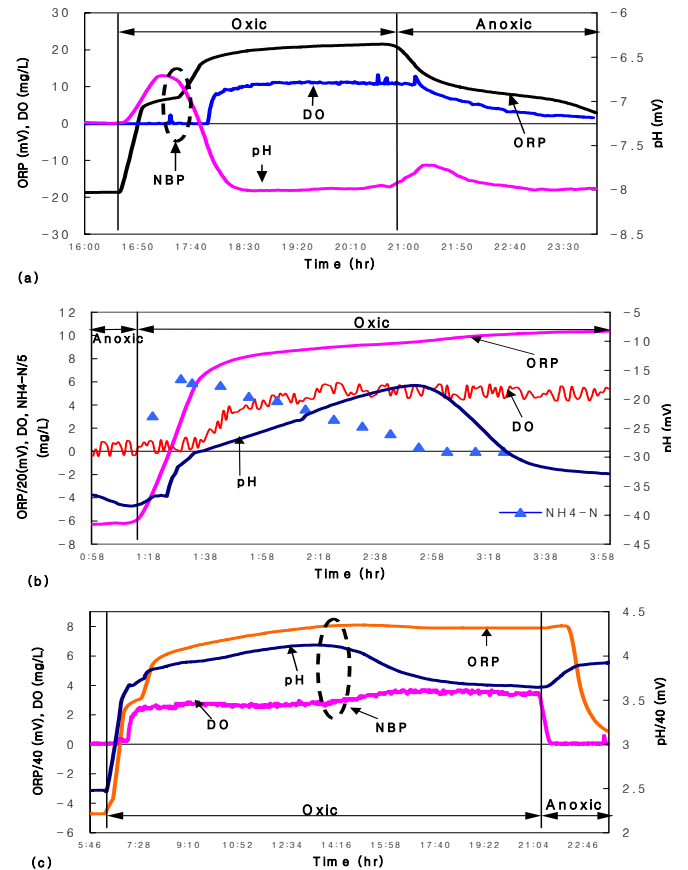

Fig. 8. ORP, $\mathrm{pH}(\mathrm{mV})$ and $\mathrm{DO}$ patterns.

로 완전질산화 시점인 $\mathrm{NBP}$ 이었음을 쉽게 확 인할 수 있다. Fig. 8b의 경우, ORP에서는 NBP 로 인식될만한 어떠한 굴곡점은 발생하지 않은 채 plateau에 도달하여 어느 지점이 $\mathrm{NBP}$ 이었는 지를 알 수 없었으며, DO curve에서는 Fig. 8a 에서와 같이 $\mathrm{O}_{2}$ 농도가 증가하면서 포화되는 굴곡점이 발생하였으나 암모니아성 질소 분석 결과 이 시점이 $\mathrm{NBP}$ 가 아니었음을 확인할 수 있었다. 그러나 $\mathrm{pH}-\mathrm{mV}$ 에서는 $\mathrm{ORP}$ 와 $\mathrm{DO}$ 가 plateau에 도달한 다음에 $\mathrm{NBP}$ 로 인식되는 굴곡 점이 늦게 발생하였는데 이 시점이 바로 질산 화 종료를 의미하는 $\mathrm{NBP}$ 이었음을 처리조 내 $\mathrm{NH}_{4}-\mathrm{N}$ 분석결과 알 수 있었다. Fig. 8c의 경우 에서는 먼저 $\mathrm{DO}$ 의 농도가 증가하여 포화되는 굴곡점이 발생한 후 ORP에서도 굴곡점이 발생 하여 $\mathrm{ORP}$ 와 $\mathrm{DO}$ 에서 $\mathrm{NBP}$ 로 인식될 만한 변화 가 발견되었으나, 이때 $\mathrm{pH}-\mathrm{mV}$ curve에서는 $\mathrm{NBP}$ 로 인식될 수 있는 어떤 변화도 발생하지 않고 오히려 $8 \mathrm{~b}$ 에서와 같이 ORP가 plateau에 도달한 후 $\mathrm{pH}-\mathrm{mV}$ 에서 $\mathrm{NBP}$ 가 발생한 것을 알 수 있다. 이 등(2001)과 임 등(1994)은 SBR 공 정에 있어서 $\mathrm{DO}$ 농도가 증가하는 시점(DO break point)과 질산화 종료시점은 정확하게 일 치하여 $\mathrm{DO}$ 는 질산화 종료의 좋은 지표가 된다 고 하였으나 본 연구를 통해 시스템의 운전조 건과 상태에 따라 $\mathrm{DO}$ 의 증가 시점과 $\mathrm{NBP}$ 의 발생시점이 일치하지 않을 수도 있음을 알 수 있었으며, $\mathrm{pH}$ 가 $\mathrm{NBP}$ 의 발생시점을 나타내는 좋은 지표가 됨을 알 수 있었다. 또한 $\mathrm{pH}$ 에서 질산화 종료시점은 쉽게 찾을 수 있으나 $\mathrm{pH}$ 의 경사도 변화는 질산화 종료시점에만 특이적으 로 나타나는 것이 아니라 전 구간에 걸쳐 다양 한 증감을 나타내기 때문에 $\mathrm{pH}$ 를 호기적 공정 의 자동제어인자로 사용하기에는 어려움이 있 고 오히려 $\mathrm{ORP}$ 의 경사도 값이 $\mathrm{DO}$ 와 $\mathrm{pH}$ 에서와 는 달리 매우 안정적이기 때문에 호기적 공정 의 자동제어인자로서 $\mathrm{ORP}$ 가 유용하다는 이 등 (2001)의 연구결과와, $\mathrm{pH}$ 의 경우 변화 범위가 크지 않아 peak point를 발견하는데 어려움이 있고 $\mathrm{CO}_{2}$ 의 탈기나 인 섭취 영향에 따라 $\mathrm{NBP}$ 가 명확하지 않다는 고 등(2002)의 보고와는 반 대로 처리시스템의 호기적 처리과정을 진단. 제어하기 위해 $\mathrm{ORP}$ 와 $\mathrm{DO}$ 를 이용할 때에는 처 리조 조건에 따라 정확한 $\mathrm{NBP}$ 발생시점을 찾 을 수 없는 경우가 발생하는 반면 $\mathrm{pH}-\mathrm{mV}$ 를 이 용 할 때는 $\mathrm{NBP}$ 가 발생하는 시점을 정확하게 찾는 것이 항상 가능하기 때문에 호기적 처리 공정을 자동제어하기 위한 인자로는 $\mathrm{ORP}$ 나 $\mathrm{DO}$ 보다는 $\mathrm{pH}-\mathrm{mV}$ 가 안정적임을 알 수 있었 다.

그러나 무산소 처리단계의 모니터나 제어를 위해서는 ORP를 이용하는 것이 안정적인데, 이 는 비록 앞에서 언급한 것과 같이 $\mathrm{ORP}, \mathrm{pH}-$ $\mathrm{mV}$ 모두에서 탈질이 완료되는 시점인 $\mathrm{NKP}$ 가 발생하나 가변적 처리 상황에서 안정성은 $\mathrm{ORP}$ 가 높기 때문이다. $2^{\text {nd }} \mathrm{SBR}$ 을 단일 $\mathrm{SBR}$ 로 이용 하여 돈사폐수를 처리하면서 얻어진 $\mathrm{ORP}$ 와 $\mathrm{pH}(\mathrm{mV})$ 의 변화 패턴을 볼 때(Fig. 9a, b), ORP curve상에서는 탈질이 완료되는 시점인 NKP가 뚜렷하게 발생하였으나, $\mathrm{pH}-\mathrm{mV}$ curve에서는 이 시점에서 아무런 변화가 일어나지 않아 $\mathrm{pH}-\mathrm{mV}$ 를 이용하여 $\mathrm{NKP}$ 를 안정적으로 인식하는 데에 는 한계가 있음을 알 수 있었으며, 경우에 따 라서는 Fig. $9 \mathrm{a}$ 에서와 같이 $\mathrm{NKP}$ 로 잘못 인식될 


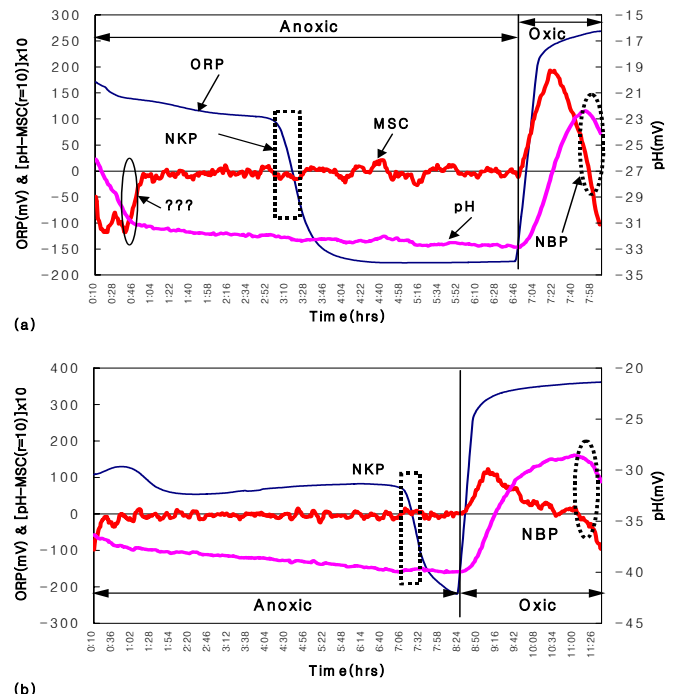

Fig. 9. ORP and $\mathrm{pH}(\mathrm{mV})$ patterns.

수 있는 변화가 $\mathrm{pH}-\mathrm{mV}$ 상에서 발생함을 알 수 있었다(?? 표시된 부분). 또한 Fig. 8b, c에서와 같이 호기적 처리중 $\mathrm{ORP}$ 에서는 $\mathrm{NBP}$ 로 인식될 만한 아무런 굴곡점이 발생하지 않는 조건에서 도 $\mathrm{pH}-\mathrm{mV}$ 에서는 매우 확실한 $\mathrm{NBP}$ 가 발생함을 확인 할 수 있었다. 이상에서 얻은 결과를 종 합하여 자동제어 인자로의 $\mathrm{ORP}, \mathrm{pH}-\mathrm{mV}, \mathrm{DO}$ 를 비교할 때 호기적 처리과정을 위한 인자로는 $\mathrm{pH}-\mathrm{mV}$ 를, 무산소 처리과정을 위한 인자로는 $\mathrm{ORP}$ 를 이용하는 것이 처리시스템의 안정적인 모니터나 자동제어에 유용함을 알 수 있었다.

\section{IV 요약 및 결론}

$\mathrm{SBR}$ 처리공정의 자동제어 인자로서의 $\mathrm{ORP}$, $\mathrm{pH}, \mathrm{DO}$ 의 안정성과 유용성을 비교 평가하였다. 시스템 운전동안 $\mathrm{ORP}$ 와 $\mathrm{pH}(\mathrm{mV})$-time profile 상 에서 오염물질의 특이적인 변화시점을 나타내 는 $\mathrm{NBP}$ 와 $\mathrm{NKP}$ 가 잘 나타났으며 이 시점은 MSC(moving slope change)를 이용하여 쉽게 인 식될 수 있는 것으로 밝혀졌다. 그러나 부하량 과 포기량 혹은 시스템 OUR이 불균형일 때는 $\mathrm{DO}$ 나 ORP-time profile 상에서 $\mathrm{NBP}$ 로 잘못 인 식될 수 있는 가짜 제어시점이 여러 번 발생하 거나 혹은 제어시점으로 인식할만한 변화가 전 혀 발생하지 않음을 알 수 있었다. 그러나
$\mathrm{pH}(\mathrm{mV})$-time profile에서는 어떤 운전조건과 상 태에서도 항상 뚜렷한 NBP가 발생하고 MSC를 이용한 제어시점 인식이 가능함을 알 수 있었 다. 따라서 호기적 처리과정 중의 시스템 진단 과 자동제어 인자로 ORP나 $\mathrm{DO}$ 보다 $\mathrm{pH}(\mathrm{mV})$ 가 안정적임을 알 수 있었다. 반면 무산소 상 태의 모니터나 제어에 있어서는 $\mathrm{pH}(\mathrm{mV})$-time profile에서 NKP를 안정적으로 인식하는 데에는 한계가 있었으나 ORP에서는 매우 안정적인 것 으로 나타나 무산소 처리과정의 진단/제어인자 로는 ORP가 다른 인자들 보다 유용함을 알 수 있었다. 이러한 결과로 미뤼 SBR 공정의 안정 적인 자동제어를 위해서는 $\mathrm{ORP}$ 혹은 $\mathrm{pH}(\mathrm{mV})$ 를 단독으로 이용하는 것 보다는 병용하는 것 이 바람직하며, 이러한 자동제어기술은 유입수 내 오염물질의 농도 변이와 운전여건에 상관없 이 항상 오염물질의 완전제거를 가능케 함은 물론 처리시간 및 처리용량의 최적화를 위한 실용적 기술이 될 것으로 판단된다.

$$
\mathrm{V} \text { 사 사 }
$$

본 연구는 2000년도 ARPC(Agricultural R\&D Promotion Center) 첨단 기술개발과제 연구비 지원에 의해 수행되었으며 이에 감사드립니다.

\section{$\mathrm{VI}$ 인 용 문 헌}

1. Al-Ghusain, I. A., Huang, J. and Lim, B. S. 1994. Using $\mathrm{pH}$ as real-time control parameter for wastewater treatment and sludge digestion processes. Wat. Sci. tech. 30(4):159-168.

2. A.P.H.A. 1995. Standard methods for the examination of water and wastewater, 19th edition, Washington, DC.

3. Chen, K. C., Chen, C. Y., Peng, J. W. and Houng, J. Y. 2002. Real-time control of an immobilizedcell reactor for wastewater treatment using ORP, Water research, 36:230-238.

4. Hao, O. J. and Huang, J. 1996. Alternating aerobicanoxic process for nitrogen removal:process evaluation, Water Environmant Research, 68(1):83-93.

5. Heduit, A. and Thevenot, D. R. 1992. Elements in the interpretation of platinum electrode potentials in biological treatment. Wat. Sci. Tech. 26(5):13351344. 
6. Koch, F. A. and Oldham, W. K. 1985. Oxidationreduction potential-a tool for monitoring, control and optimization of biological nutrient removal system. Wat. Sci. Tech. 17:259-281.

7. Lo, C. K., Yu, C. W., Tam, N. F. Y. and Traynor, S. 1994. Enhanced nutrient removal by oxidation-reduction potential(ORP) controlled aeration in a laboratory scale extended aeration treatment system. Wat. Sci. tech. 28(10):2087-2094.

8. Okada, M., Sudo, R. and Terazona, K. 1984. Removal of nutrients and BOD from soybean fermentation wastewater in a ten-year-old sequencing batch reactor activated sludge process. Wat. Sci. Tech. 22(9):85-93.

9. Ra, C. S., Lo, K. V., Shin, J. S., Oh, J. S. and Hong, B. J. 2000. Biological nutrient removal with an internal organic carbon source in piggery wastewater treatment. Water research, 34(3):965-973.

10. Ra, C. S., Lo, K. V. and Mavinic, D. S. 1999. Control of a swine manure treatment process using a specific feature of oxidation reduction potential. Bioresource technology. 70:117-127.

11. Ra, C. S., Lo, K. V. and Mavinic, D. S. 1998. Real-time control of two-stage sequencing batch reactor system for the treatment of animal wastewater. Environmental Technology. 19:343-356.
12. Yu, R. F., Liaw, S. L., Chang, C. N., Lu, H. J. and Cheng, W. Y. 1997. Monitoring and control using on-line ORP on the continuous-flow activated sludge batch reactor system. Wat. Sci. Tech. 35:5766.

13. Wareham, D. G., Hall, K. J. and Mavinic, D. S. 1993. Real-time control of aerobic-anoxic sludge digestion using ORP. J. Environ. Eng., 119:120136.

14. 고광백, 서준석. 2002. $\mathrm{ORP}$ 와 $\mathrm{pH}$ 측정에 의한 간 헐폭기 고도처리 공정 제어의 평가. 한국물환경 확회지. 18(4):401-409.

15. 서인석, 김병균, 박승국. 2000. 간헐포기 형태의 활성슬러지 공정에서 질소, 인 및 $\mathrm{pH}, \mathrm{ORP}$ 의 거 동에 관한 연구. 한국물환경학회지. 16(1):65-76.

16. 이병헌, 강성재, 감성희, 이동석, 유평종. 2001. 자동제어 $\mathrm{AOAS} \mathrm{SBR}$ 공정의 영양소 제거. 한국 물환경학회지. 17(6):703-709.

17. 임봉수. 1994. pH 제어를 이용한 선택적인 Aerobicanoxic 슬러지 소화. 한국물환경학회지. 10(1):56-61.

(접수일자 : 2003. 10. 9. / 채택일자 : 2004. 2. 9.) 